\title{
Tool wear in dry helical milling for hole-making in AISI H13 hardened steel
}

Robson Bruno Dutra Pereira ${ }^{1 *}$, Carlos Henrique Lauro ${ }^{1}$, Lincoln Cardoso Brandão ${ }^{1}$, João Roberto Ferreira ${ }^{2}$, J. Paulo Davim ${ }^{3}$

*Corresponding author: robsondutra@ufsj.edu.br

${ }^{1}$ Department of Mechanical Engineering - Industrial Engineering, Federal University of São João del Rei (UFSJ), 170 Frei Orlando Square, São João del Rei, MG 36880-000, Brazil

${ }^{2}$ Institute of Industrial Engineering and Management, Federal University of Itajubá (UNIFEI), 1303 BPS Avenue, Itajubá, MG 37500-903, Brazil

${ }^{3}$ Department of Mechanical Engineering, University of Aveiro, Campus Santiago, 3810193 Aveiro, Portugal

\begin{abstract}
Helical milling is a hole-making process which can be applied to achieve a high quality finished boreholes in hardened steels. Due to the drilling process limitations, which are intensified when applied in hardened steels, the helical milling process can be applied on hole-making tasks in moulds and dies industry, since milling have been widely applied in moulds and dies machining to replace high-cost operations like grinding and electrical discharge machining. However, to succeed in achieving high-quality boreholes in hardened parts, which presents high added value due to previous operations, tool wear in the helical milling of hardened steels should be more investigated. In the present study dry helical milling tool life tests were conducted in AISI H13 hardened steel parts, varying the cutting velocity. The flank wear on frontal cutting edges was progressively measured through optical microscopy, and SEM/EDS was performed in frontal and peripheral worn cutting edges. The wear occurred progressively in the flank of the frontal cutting edges with adhesion and oxidation as main wear mechanisms. In the peripheral edges, it was observed coating loss, adhesion of workpiece material in the tool clearance surface, besides fracture in the tool nose flank with the highest cutting velocity. A nested ANOVA was performed to evaluate the burr height in the borehole exit. The tool life stage was statistically significant in the burr height.
\end{abstract}

\section{Keywords}

Helical milling; tool wear; tool life; hardened steel; burr formation. 


\section{Introduction}

Helical milling is a hole-making process which can be applied to attain boreholes in hardened steels with high quality, feasible productivity and with a low wear rate. In helical milling, the mill tool follows a helical path with concomitant rotational movement around its own axis [1]. The helical milling allies continuous and discontinuous cut, with frontal and peripheral cutting edges [2], respectively, guaranteeing good chip formation, evacuation and breaking [3], low cutting forces [4], besides good fluid conditions [5]. As a consequence of the process kinematics, the borehole diameter can be defined by adjusting the helical diameter without changing the tool, reducing tool inventory, and reducing setups [6]. In hardened steels, generally applied in the moulds and dies industry, the application of the conventional drilling process presents several problems, from unpredictable catastrophic failure of the drill cutting edges to high thrust forces levels, besides difficult chip evacuation, hampering to achieve reliability due to the high added value of parts which will generally undergo hole-making operations in the last stages of manufacturing [7]. Consequently, the helical milling process may be applied in hardened steels [3,8] and other difficult to cut materials [9-11] to achieve finished boreholes in just one operation, guaranteeing low cutting forces, good borehole quality in terms of dimensional, geometrical and microgeometrical tolerances [12], besides the opportunity of monitoring the tool wear progression [13].

Some recent studies addressed the tool wear in the helical milling operation. Li et al. [14] studied the tool wear of carbide end mills with TiAlN coating in the helical milling of the Ti-6Al-4V alloy. The main wear mechanisms were chipping/fracture, diffusion, and oxidation on frontal cutting edges. Burr levels on the exit of boreholes were correlated with average flank wear on frontal cutting edges. Qin et al. [15] also studied the tool wear in the helical milling of Ti-6Al-4V comparing tungsten carbide (WC) tools coated with TiAlN and coated with diamond. The observed tool wear mechanisms were adhesion, oxidation, coating flaking, and chipping. Considering the flank wear of frontal cutting edges, the TiAlN-coated tool presented higher life than the diamond-coated tool during helical milling of the Ti-6Al-4V alloy. Tool wear in the helical milling of CFRP was investigated by Wang et al. [16]. Abrasion, adhesion, coating flanking were the main wear mechanisms. The delamination level in the entry of boreholes increased along with the progression of the tool wear. Zhao et al. [17] studied the tool wear in helical milling and drilling of Ti-6Al-4V. While in drilling the main failure modes were due to fracture, non- 
uniform flank wear and micro-chipping, in helical milling the identified wear mechanisms were crater, adhesion, chipping, and flaking. With helical milling, it was obtained more than double of boreholes when compared with drilling.

Iyer et al. [3] studied the tool wear in drilling and helical milling of AISI hardened D2 steel (60 HRC). Testing four drill types, three twist drills presented severe fracture after making in the first hole, while one of the twist drills presented flank wear higher than $0.3 \mathrm{~mm}$ also after the first borehole. In helical milling, it was obtained 10 boreholes with a TiCN-coated indexable carbide insert tool and 16 boreholes with a TiAlN-coated ball nose carbide end mill. In helical milling, the wear occurred progressively with attrition and microchipping in the flank of the frontal cutting edges. The authors used aircooling to assist in chip removal.

The hardened steels are susceptible to quenching heat treatment to achieve high hardness levels, from 52 to $62 \mathrm{HRC}$ [18]. The high hardness of the hardened steels results in high cutting forces and severe friction in the tool-chip contact area [19]. In the moulds and dies industry, the process of milling after the heat treatment has been applied to save cycle times, to avoid setups and high-cost machining operations such as grinding and electrical discharge machining [20,21]. Consequently, to overcome the challenges of hard milling is mandatory. More specifically, the helical milling of these hard-to-cut materials can also present better results and lower costs when compared to drilling.

Since the tool wear in the helical milling of hardened steels still have been little researched, the present work is on tool wear and life in dry helical milling for hole-making of AISI H13 hardened steel. This study has novelty in the tool wear mechanisms investigation through SEM/EDS, besides the study of the burr height evolution in the exit hole with regard to the tool wear evolution. The tool wear curves were also provided, and the Taylor tool life Equation was calculated to give a notion of the tool wear resistance when applied to the helical milling in the hard-to-cut material AISI H13 hardened steel.

\section{Experimental procedure}

Helical milling tool life tests were carried out at the machining and tribology research group (MACTRIB) laboratory at University of Aveiro. The tests were performed in a machining centre model VCE500 from Mikron ${ }^{\circledR}$, with $11 \mathrm{~kW}$ of power and maximum spindle speed of 7500 RPM. To measure the wear progression in the tool during helical milling hole-making operation it was used an optical microscope TM 510 from Mitutoyo ${ }^{\circledR}$ 
with camera Moticam 2 and image acquisition software Images Plus 2.0 ML both from Motic ${ }^{\circledR}$, all owned by MACTRIB. The experimental setup is exposed in Figure 1.

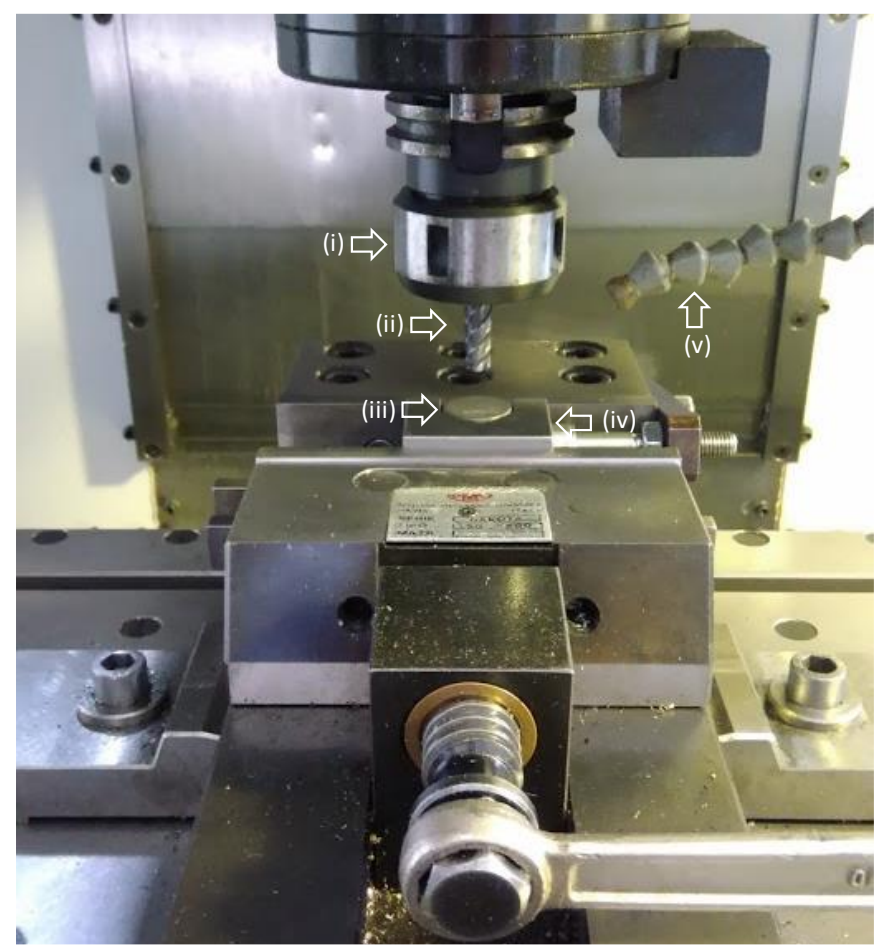

Figure 1. Experimental Setup of helical milling tool life tests (i) tool holder, (ii) end mill, (iii) workpiece, (iv) fixture device, (v) air cooling system

The tool used in the helical milling tool life tests was a solid end mill ISO/ANSI R215.H4-10050DAC03H 1610 from Sandvik®, illustrated in Figure 2. This tool was chosen due to the possibility of high feed in the tangential direction, due to the difficulty of feed axially in hard milling. The tool presents $D_{t}=10 \mathrm{~mm}$ diameter, four cutting edges, and double nose radius, guaranteeing the possibility of duplicate the tangential feed in the helical milling. The tool presents useful length up to $26 \mathrm{~mm}$, helix angle $\beta_{h}=50^{\circ}$, tool nose of $1.5 \mathrm{~mm}$, tool cutting edge angle $\kappa_{R}=32.69^{\circ}$, rake face without chip-breaker, and a maximum overhang of $32 \mathrm{~mm}$. However, the tool presents a constraint of a maximum axial depth of cut, $a_{p(m a ́ x)}=0.3 \mathrm{~mm}$ and maximum ramp angle of $3^{\circ}$. These constraints were respected in all tool life tests when picking axial and tangential feed per tooth, $f_{z a}$ and $f_{z t}$, both in [mm/tooth], which are related to maximum axial cutting depth, $a_{p}{ }^{*}$ in [mm], according to the Equation 1 [2], where $\alpha$ is the angle of helix considering the tool path, $D_{b}$ is the borehole diameter in [mm], and $D_{h}=D_{b}-D_{t}$ is the diameter of the helical path, in $[\mathrm{mm}]$. It is important to mention that $f_{z t}$ is calculated with respect to the hole diameter. 
The tool material, which is indicated for hard milling, is GC 1610 Sandvik ${ }^{\circledR}$ designation, ISO $\mathrm{H}$, carbide, with thin $(\mathrm{Ti}, \mathrm{Al}) \mathrm{N}_{2}$ PVD coating. The substrate presents grain distribution in gradient, combining improved resistance to plastic deformation and toughness of cutting edge. The tool does not present chip breaker and its angles are summarized in Table 1. All helical milling tool life tests were carried out with down cut direction, with air for cooling and chip removal.

$a_{p}^{*}=\tan (\alpha) \cdot \pi \cdot D_{h}=\frac{f_{z a} \cdot \pi \cdot D_{b}}{f_{z t}}$

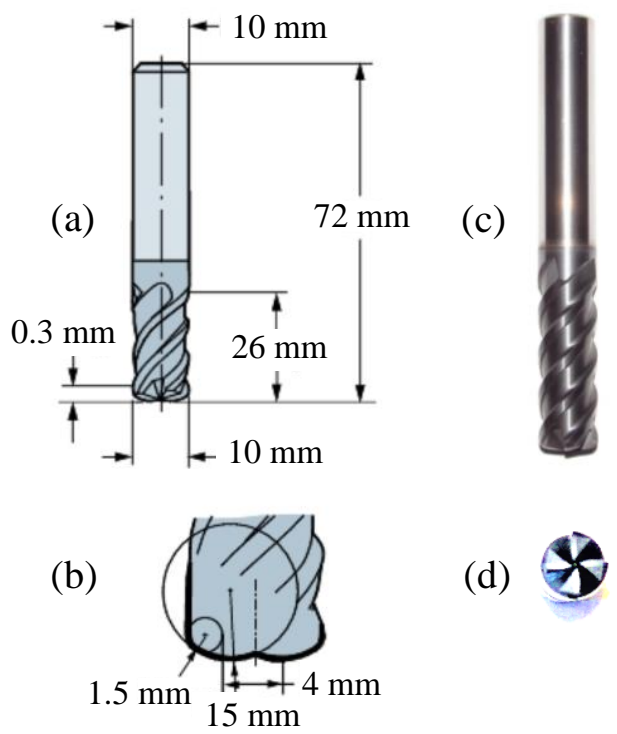

Figure 2. End mill code R215.H4-10050DAC03H 1610 from Sandvik®; (a) dimensions; (b) double nose detail; (c) peripheral edges; (d) frontal edges
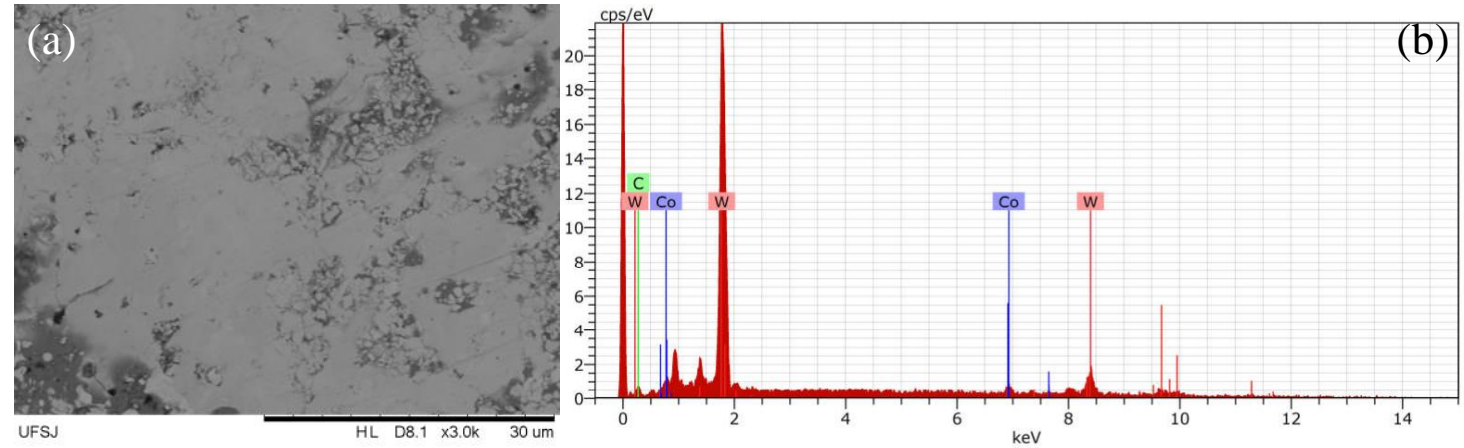

Figure 3. End mill code R215.H4-10050DAC03H 1610 from Sandvik® (a) SEM; (b) EDS 
Figure 3(a) shows a SEM image of the tool R215.H4-10050DAC03H 1610 from Sandvik®, associated with the EDS spectra in Figure 3(b). As observed in Figure 3(b) the composition of the carbide tool is WC-Co. A small quantity of O was omitted of the EDS analysis.

Table 1. End mill angles. ISO/ANSI R215.H4-10050DAC03H 1610

\begin{tabular}{cccc}
\hline$\beta_{h}$ (helix) & $\kappa_{R}$ & $\gamma_{f}$ & $\gamma_{p}$ \\
\hline $50^{\circ}$ & $32.69^{\circ}$ & $-18^{\circ}$ & $6^{\circ}$ \\
\hline
\end{tabular}

The AISI H13 hardened steel workpieces were cooled in a vacuum oven and supplied by Ramada $A c ̧ o s \AA$. The chemical composition of the material provided by Ramada Aços® is summarized in Table 2. The AISI H13, DIN X40 CrMoV5-1 designation, is recommended for applications in aluminium extrusion dies, and moulds for thermoplastics. These applications present several hole-making necessities which makes feasible the study of an efficient hole-making operation such as helical milling.

Table 2. Chemical composition (\%) of AISI H13 supplied by Ramada Aços®

\begin{tabular}{cccccc}
\hline $\mathrm{C}$ & $\mathrm{Mn}$ & $\mathrm{Si}$ & $\mathrm{Cr}$ & $\mathrm{Mo}$ & $\mathrm{V}$ \\
\hline 0.4 & 0.4 & 1.0 & 5.2 & 1.3 & 1.0 \\
\hline
\end{tabular}

Figure 4(a) shows a 3000 times magnification SEM image of the AISI H13 hardened steel workpiece provided by Ramada Aços ${ }^{\circledR}$ with the EDS spectra in Figure 4(b). As observed in the EDS, Figure 4(b), the elements of the material Fe, C, Mn, Si Cr, Mo, and V were identified in EDS.
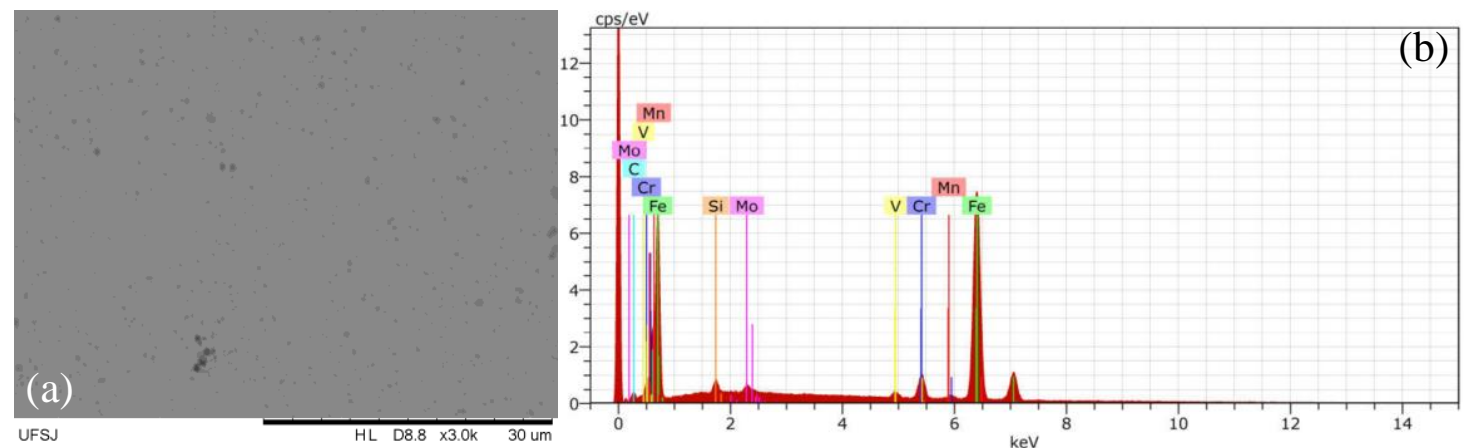

Figure 4. AISI H13 hardened steel workpiece; (a) SEM; (b) EDS 
Figure 5 shows the hardness profile of the AISI H13 hardened steel workpieces with correspondent data in Table 3. The hardness profile was obtained considering two workpieces which were measured in four positions equidistant of $3 \mathrm{~mm}$ starting from the centre, resulting in four measurements positions. Since the workpieces diameter is 25.4 $\mathrm{mm}$, in a radius of $12.7 \mathrm{~mm}$, it was possible to measure in only four positions. As it can be seen in the Figure 5, it was collected one measurement in the centre of each workpiece and three measurements in each one of the other radial positions. The workpieces presented lower levels of hardness nearby the centre with more than $56 \mathrm{HRC}$ from $6 \mathrm{~mm}$ from the centre to the periphery.

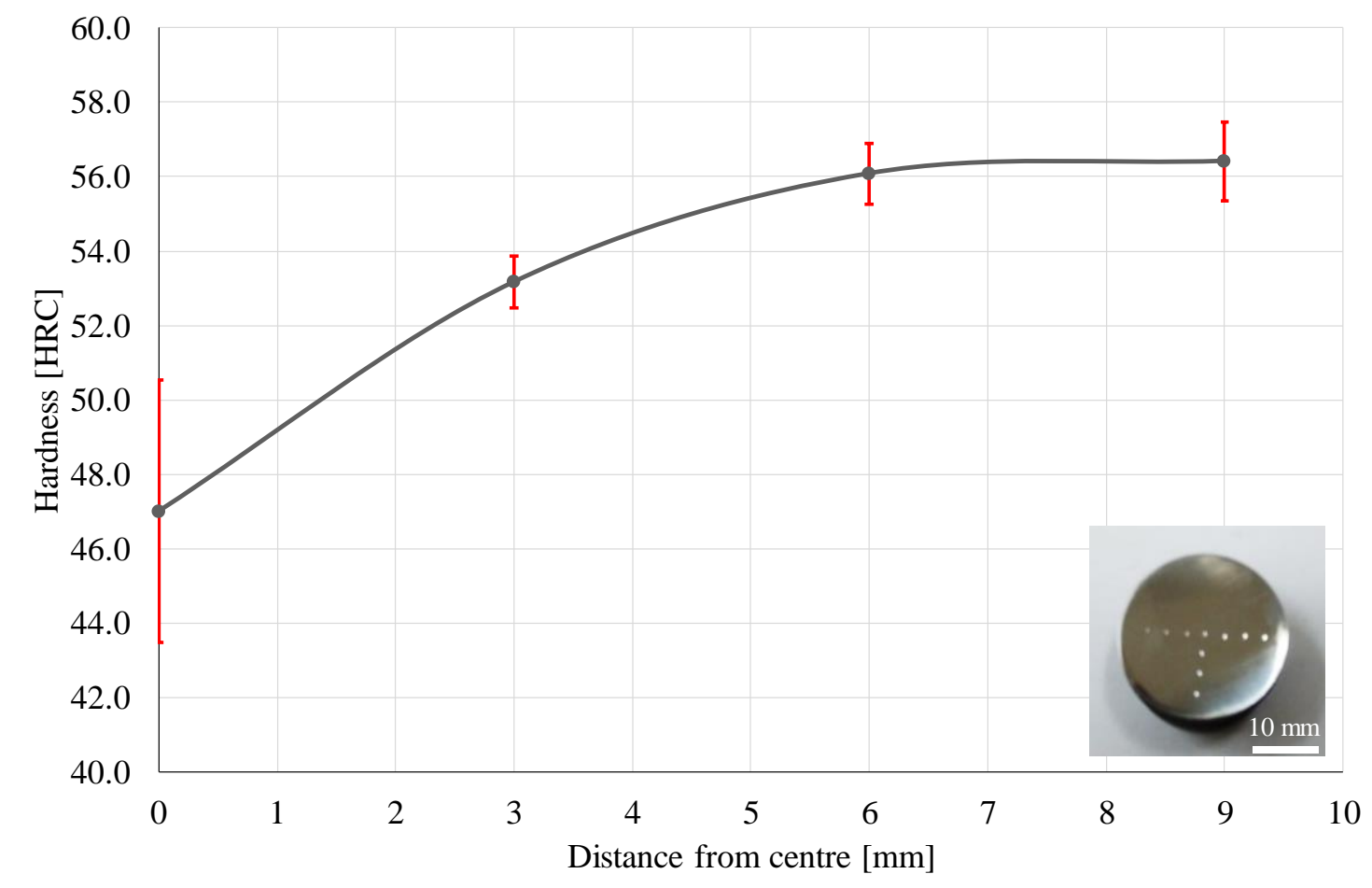

Figure 5. Hardness profile of AISI H13 hardened steel

Table 3. Hardness profile data

\begin{tabular}{lcccc}
\hline Distance from centre [mm] & 0 & 3 & 6 & 9 \\
\hline Hardness [HRC] & 47.0 & 53.2 & 56.1 & 56.4 \\
std dev [HRC] & 3.5 & 0.7 & 0.8 & 1.1 \\
\hline
\end{tabular}

The helical milling tool life tests were carried out in cylindrical workpieces of AISI H13 hardened steel with $25.4 \mathrm{~mm}$ of diameter and $20 \mathrm{~mm}$ of height, without prehole. Through boreholes with $D_{b}=18 \mathrm{~mm}$ of diameter were obtained in all helical milling tests. As the tool diameter is $D_{t}=10 \mathrm{~mm}$, the helical diameter was $D_{h}=D_{b}-D_{t}=8 \mathrm{~mm}$, 
with eccentricity between tool centre point and borehole centre point, $e=D_{h} / 2=4 \mathrm{~mm}$. Figure 6 shows the helical milling tool life tests in AISI H13 hardened steel schematic drawing, showing the workpiece dimensions, borehole, tool, and helical diameters.
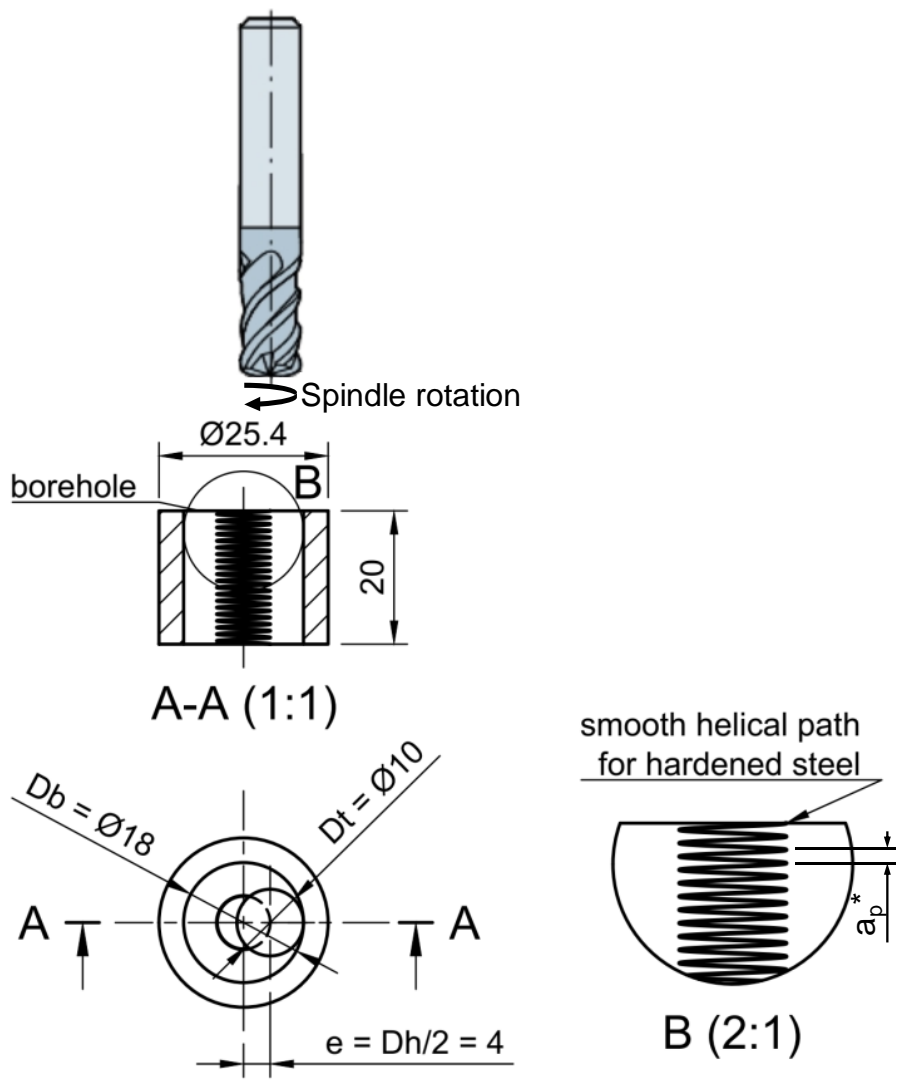

Figure 6. Schematic drawing of helical milling tool life tests

After the helical milling tool life tests with tool wear monitoring with optical microscopy, the worn end mills were cut in the company Cormol® by wire electroerosion to fit in the scanning electron microscope camera. To evaluate the tool wear mechanisms, it was used a scanning electron microscope (SEM) TM3000 from Hitachi ${ }^{\circledR}$ with energydispersive X-ray spectroscopy - EDS model Xflash Minsve from Bruker®. The SEMEDS is from the microscope laboratory of the mechanical engineering department of the Federal University of São João del-Rei (UFSJ).

A Form Talysurf Intra from Taylor Hobson ${ }^{\circledR}$ from the Metrology laboratory of UFSJ was used to measure the burr height of the boreholes. The burr measurement setup is exposed in Figure 7. 


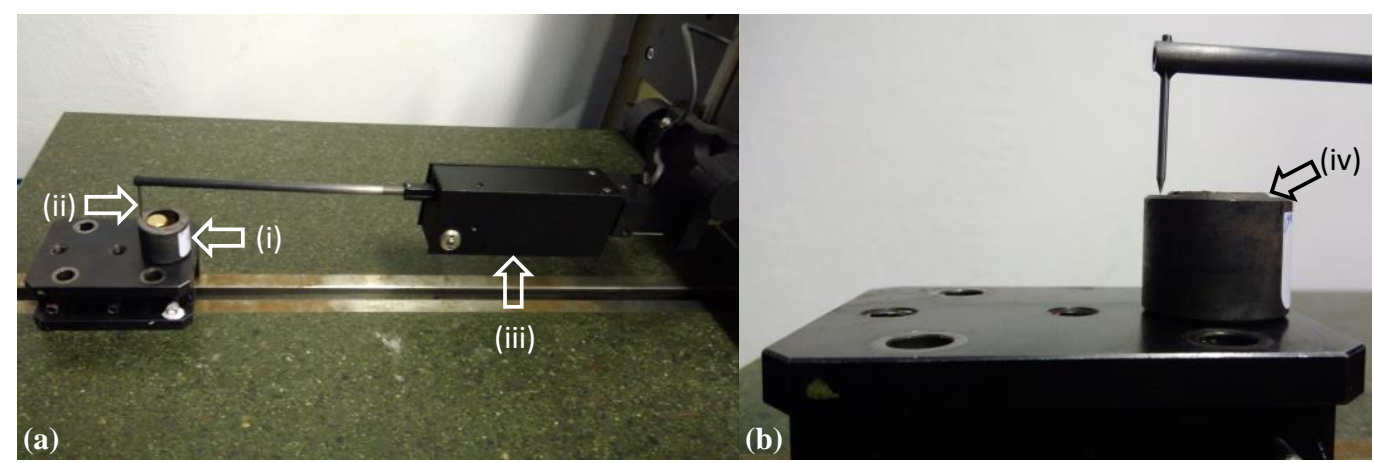

Figure 7. (a) Burr measurement, (i) workpiece, (ii) conical tip, (iii) wide range pick-up (b) detail with (iv) borehole exit-burr

The ISO 8688-1 - Tool life testing in milling standard from 1989 was referred. However, as in this study the tool life tests were performed considering the helical milling process, the recommendations of the standard were not applied.

In the helical milling tool life tests, the average flank wear of the frontal cutting edges were measured progressively. The end of tool life criteria was $\mathrm{VB}_{\mathrm{B}}=0.15 \mathrm{~mm}$. Two tools were worn until the end of the life with distinct cutting velocities, according to the Table 4 . The cutting velocity adopted in the condition 1 was $v_{c}=60 / \mathrm{min}$ to respect the tool manufacturer's recommendation bounds. The condition 2 was set to test an extreme condition defined through preliminary tests as a borderline cutting velocity in the helical milling of AISI H13 steel with the selected cutting tool. It is known that the cutting velocity is the cutting condition more influent on tool wear since its increase accelerates the wear mechanisms related with friction and temperature.

Table 4. Helical milling tool life tests cutting conditions

\begin{tabular}{cccc}
\hline \multirow{2}{*}{ Tests } & $f_{z a}$ & $f_{z t}$ & $v_{c}$ \\
\cline { 2 - 4 } & $\mu \mathrm{m} / \mathrm{rot}$ & $\mathrm{mm} / \mathrm{rot}$ & $\mathrm{m} / \mathrm{min}$ \\
\hline Condition 1 & 0.15 & 0.15 & $\begin{array}{c}60 \\
\text { Condition 2 }\end{array}$ \\
\hline
\end{tabular}

As it was observed, the burr formation with the wear progression, the burr height was measured in the workpieces machined in the beginning, middle and end of the tool life, three workpieces for each tool life stage considering the two conditions in Table 4. For each workpiece, the burr height was measured in three positions angularly equidistant from $120^{\circ}$, as illustrated in Figure 8. 


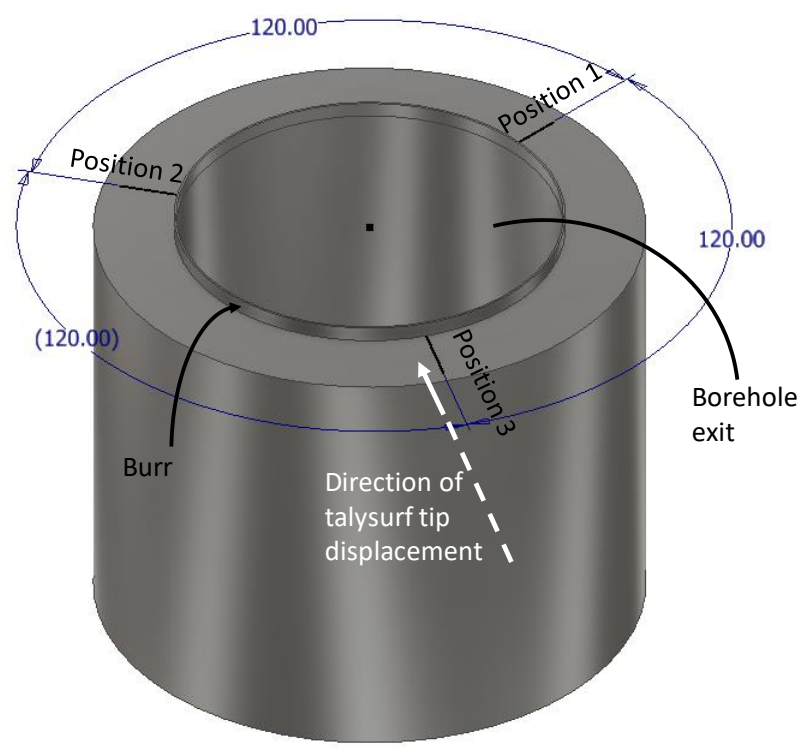

Figure 8. Burr height measurement positions

To evaluate the behaviour of burr height with regard to $v_{c}$ and tool life stage, the two-stage nested analysis of variance (ANOVA) was performed considering the levels of the factor stage nested in the levels of the factor $v_{c}$, since at different $v_{c}$ levels the tool life stages were achieved in different time periods. The factor stage was considered random, since it was our interest to made conclusions about the complete tool life period of the tool, considering only small evaluated periods in the beginning, middle and end of the tool life. The factor $v_{c}$ was considered fixed.

The cap generated at the borehole exit were collected and the thickness values were measured using a micrometer from Mitutoyo ${ }^{\circledR}$ with resolution of $0.01 \mathrm{~mm}$.

The statistical analyses with the assumptions tests were conducted considering a significance level $\alpha=0.05$ using the software Minitab ${ }^{\circledR} 17$.

\section{Results and discussion}

Figure 9 plots the wear curves for the helical milling tool life tests in the AISI H13 hardened steel. These curves were constructed considering the average flank wear of the frontal end mill edges, $\mathrm{VB}_{\mathrm{B}}$, evaluated through the optical microscope, camera and image acquisition software. The flank wear in the frontal cutting edges defined the tool life end. Considering $\mathrm{VB}_{\mathrm{B}}=0.15 \mathrm{~mm}$ as the end of tool life criteria, with $v_{c}=60 \mathrm{~m} / \mathrm{min} 37$ boreholes with $20 \mathrm{~mm}$ depth were machined, with total machining time $646 \mathrm{~min}$, while for $v_{c}=175 \mathrm{~m} / \mathrm{min} 19$ boreholes were machined also with $20 \mathrm{~mm}$ depth, with $185.14 \mathrm{~min}$ 
total machining time. As the workpieces high hardness levels, the helical milling process presented high capability on achieving a feasible tool life, certifying the possibility of achieving several boreholes until the end of the tool life, decreasing tool costs.

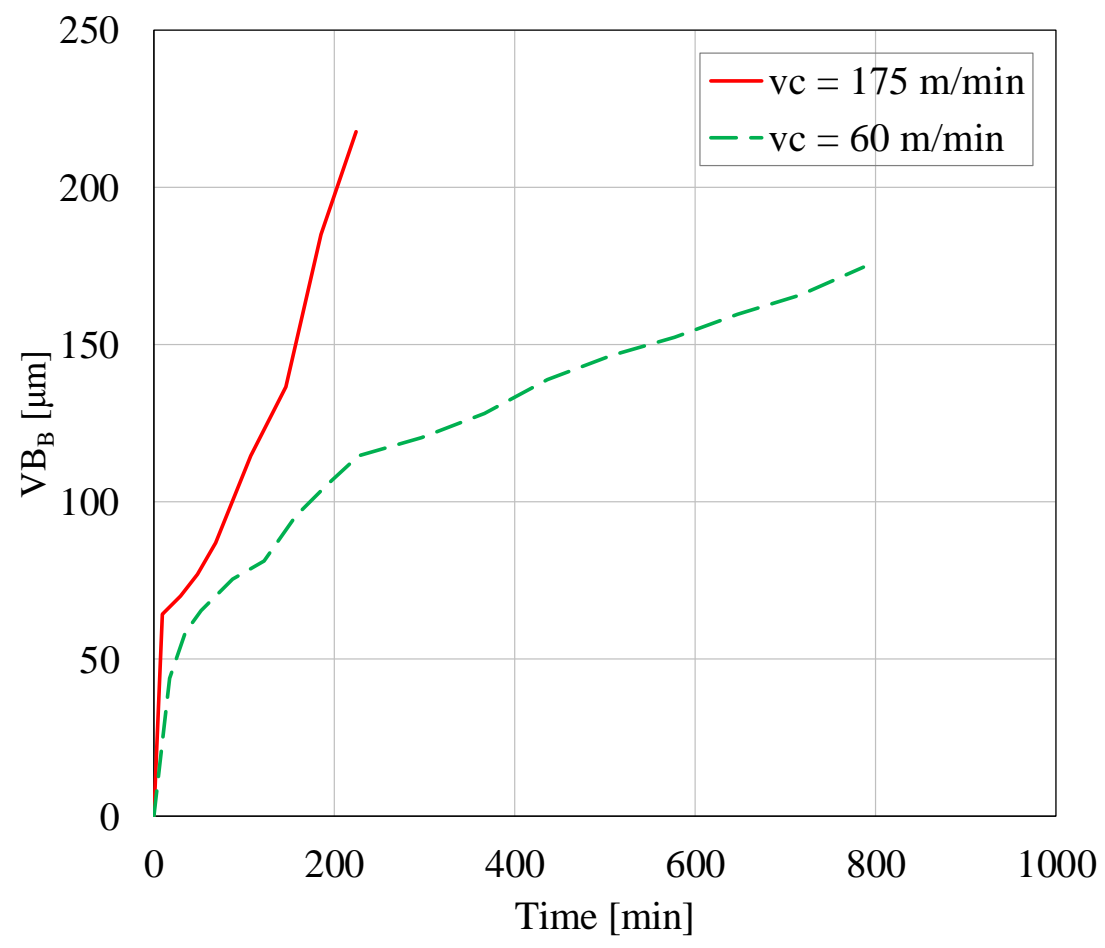

Figure 9. Wear curves, tool ISO/ANSI R215.H4-10050DAC03H 1610 in helical milling of AISI H13 hardened steel

Figure 10 shows the wear curves with confidence intervals obtained considering the pooled standard deviation for both cutting velocities in different panels.

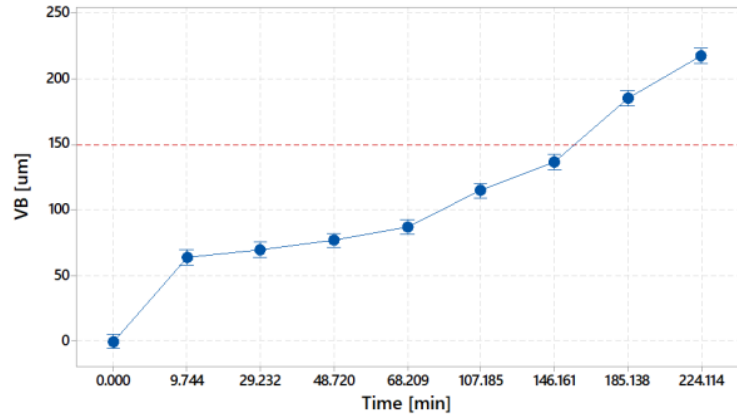

(a)

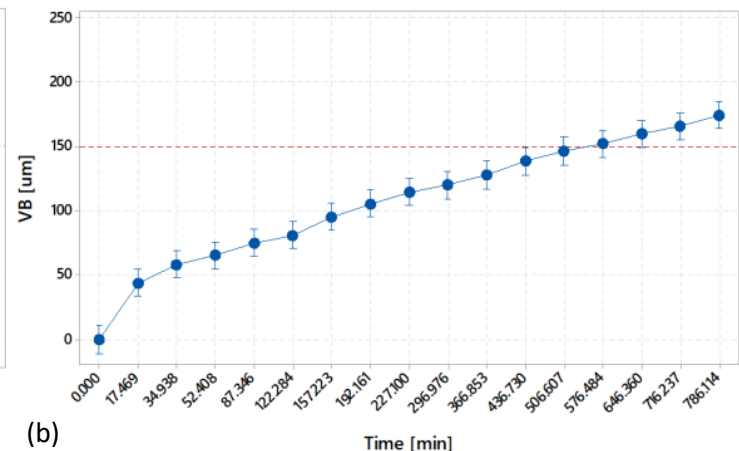

(b)

Figure 10. Wear curves with confidence intervals (a) $v_{c}=60 \mathrm{~m} / \mathrm{min}$; (b) $v_{c}=175 \mathrm{~m} / \mathrm{min}$

Considering the tool life criteria $\mathrm{VB}=0.15 \mathrm{~mm}$ for the two cutting velocities, the average tool life time is summarized in Table 5. Through these values, the Taylor's tool 
life equation, $T v_{c}{ }^{x}=k$ was obtained with $x=1.064$ and $k=39059.61$. Although the simplicity of this Equation, it may serve as a reference for the machinist about the tool wear resistance of the tool with regard to the cutting velocity in the helical milling of AISI H13 hardened steel, considering the experimental conditions applied in the tool life tests.

Table 5. Tool life time $(T)$ with tool life criteria $V B=0,15 \mathrm{~mm}$

\begin{tabular}{cc}
\hline$v_{c}[\mathrm{~m} / \mathrm{min}]$ & $\mathrm{T}[\mathrm{min}]$ \\
\hline 60 & 550 \\
175 & 160 \\
\hline
\end{tabular}

Figure 11 presents images obtained by SEM, Figure 11(a), and by the optical microscope, Figure 11(b), of the flank wear of the frontal cutting edges for $v_{c}=60 \mathrm{~m} / \mathrm{min}$. It can be observed that the tool wear was regular in the flank face of the frontal cutting edges. The regions (i) and (ii) in Figure 11(a) were evaluated with superior magnitude by SEM, and EDS was also performed to support the wear mechanisms definition.

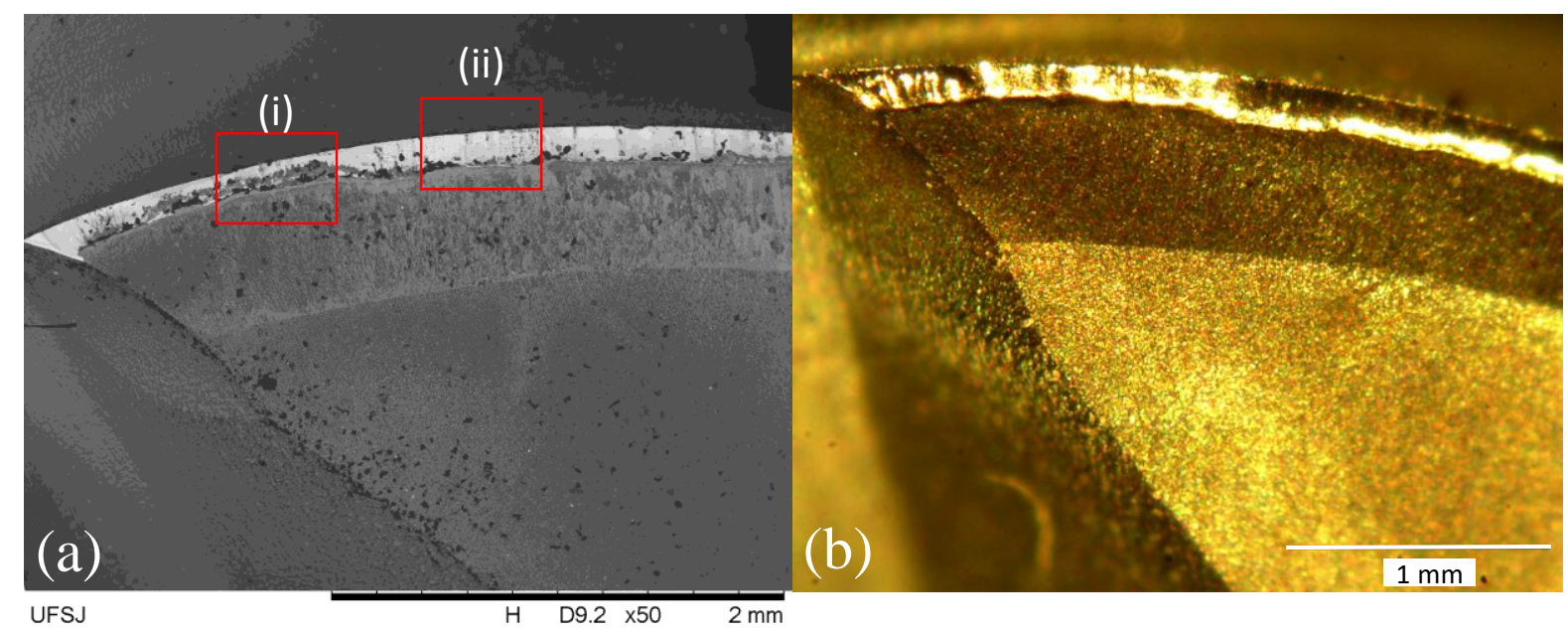

Figure 11. Flank wear, $v_{c}=60 \mathrm{~m} / \mathrm{min}$ (a) SEM, (b) optical microscope

Figure 12(a) presents a magnified SEM image of the area (i) of Figure 9(a). The EDS spectrum of the region (iv) is at Figure 12(b). This tool was worn with $v_{c}=60 \mathrm{~m} / \mathrm{min}$. The atoms with the associated percentage in mass and atomic are summarized in Table 6. The presence of $\mathrm{Fe}$ and $\mathrm{Cr}$ in the region (iv), elements present in the chemical composition of the AISI H13 steel, indicates adhesion in this region. WC is the main carbide composing the substrate of the tool, while $\mathrm{N}$ is present in the tool coating. The presence of $\mathrm{O}$ indicates the formation of oxides with other compounds with poor bonding strength 
and low hardness resulting from the loss of carbides, as explained by Qin et al. [15]. However, some amount of the oxidation may have occurred after the tool life tests, in the time interval between tests and measurements by SEM/EDS.
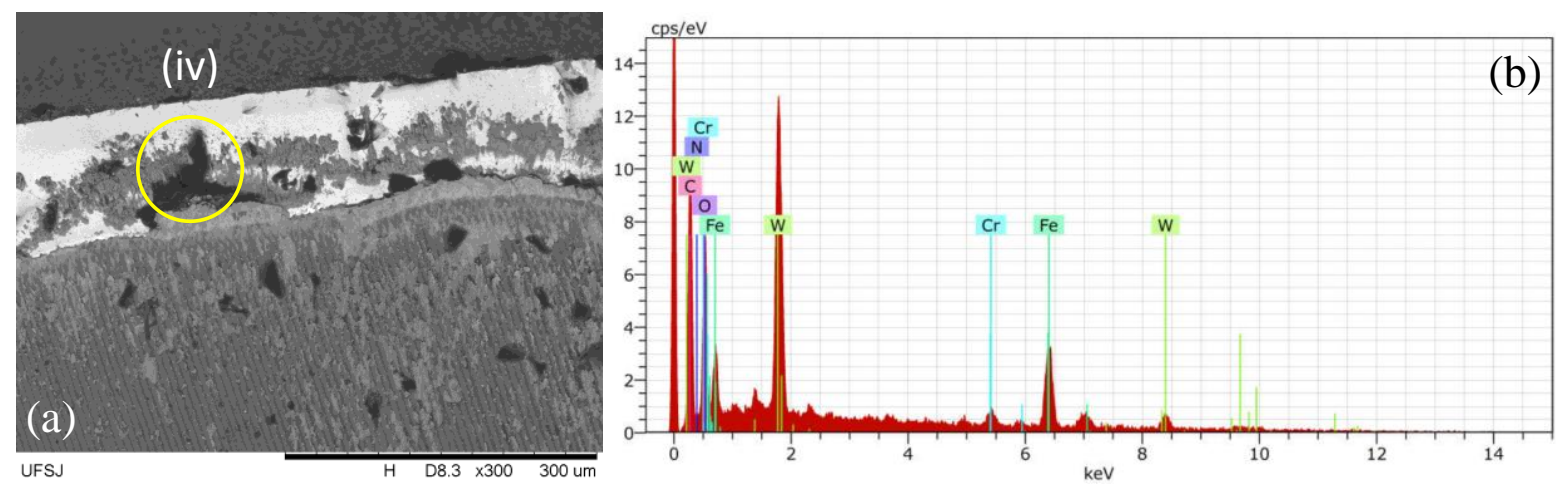

Figure 12. (a) SEM of the region (i) Figure 11(a); (b) EDS of the region (iv)

Table 6. Chemical elements identified by EDS in the region (iv)

\begin{tabular}{lcccccc}
\hline \multicolumn{1}{c}{ Element } & $\mathrm{C}$ & $\mathrm{O}$ & $\mathrm{Fe}$ & $\mathrm{W}$ & $\mathrm{N}$ & $\mathrm{Cr}$ \\
\hline \% mass & 33.35 & 22.13 & 21.48 & 15.20 & 5.39 & 2.46 \\
\% atomic & 54.88 & 27.34 & 7.60 & 1.63 & 7.61 & 0.93 \\
\hline
\end{tabular}

Figure 13 presents the magnification obtained by SEM of the area (ii) from Figure 9. EDS was conducted for the areas (v) and (vi) with spectra obtained exposed in the Figures 13(b) and 13(c) respectively. Table 7 summarizes the percentage of the components found through the EDS analysis. The main elements were $\mathrm{W}$ and $\mathrm{C}$, indicating the presence of tungsten carbide, WC. This carbide presents white colour with the higher percentage in the region (v) than in region (vi), indicating the worn region of the flank of the frontal cutting edge. The presence of oxygen indicates oxidation, the presence of nitrogen in low quantity the tool coating composition, while the presence of Fe in lowest percentage also indicates adhesion, in a small amount.

Table 7. Chemical elements identified by EDS in the regions (v) and (vi)

\begin{tabular}{ccccccc}
\hline & Element & $\mathrm{W}$ & $\mathrm{C}$ & $\mathrm{O}$ & $\mathrm{N}$ & $\mathrm{Fe}$ \\
\hline \multirow{2}{*}{$\mathrm{v}$} & \% mass & 76.66 & 14.64 & 5.11 & 1.92 & 1.66 \\
& \% atomic & 19.65 & 57.43 & 15.05 & 6.47 & 1.40 \\
\hline \multirow{2}{*}{ vi } & \% mass & 58.29 & 20.96 & 12.15 & - & 8.61 \\
& \% atomic & 10.65 & 58.65 & 25.52 & - & 5.18 \\
\hline
\end{tabular}



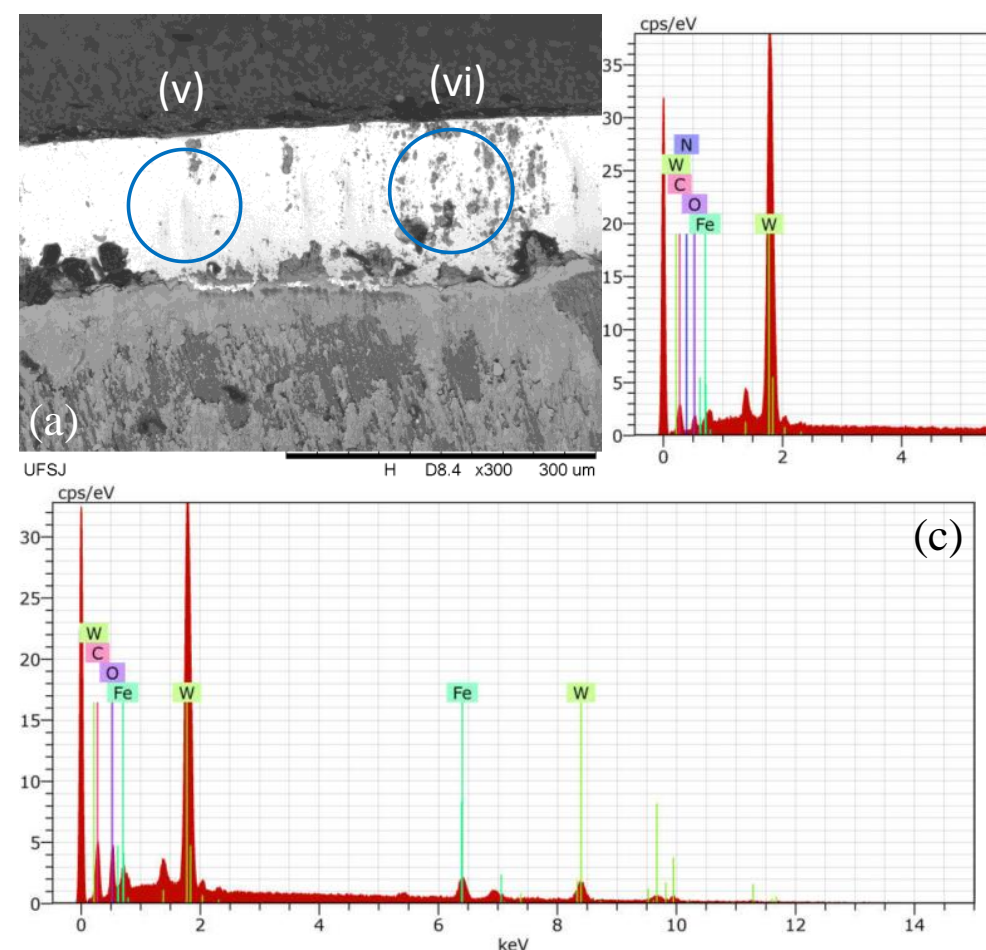

Figure 13. (a) SEM of the region (ii) from Figure 11(a); (b) EDS from region (v); (c) EDS from region (vi)

Figure 14 presents images of the flank wear of one of the frontal cutting edges of the tool after the end of helical milling tool life tests with $v_{c}=175 \mathrm{~m} / \mathrm{min}$. The flank wear was highest approximately in the point with a distance equal to $1.5 \mathrm{~mm}$ from the tool centre.

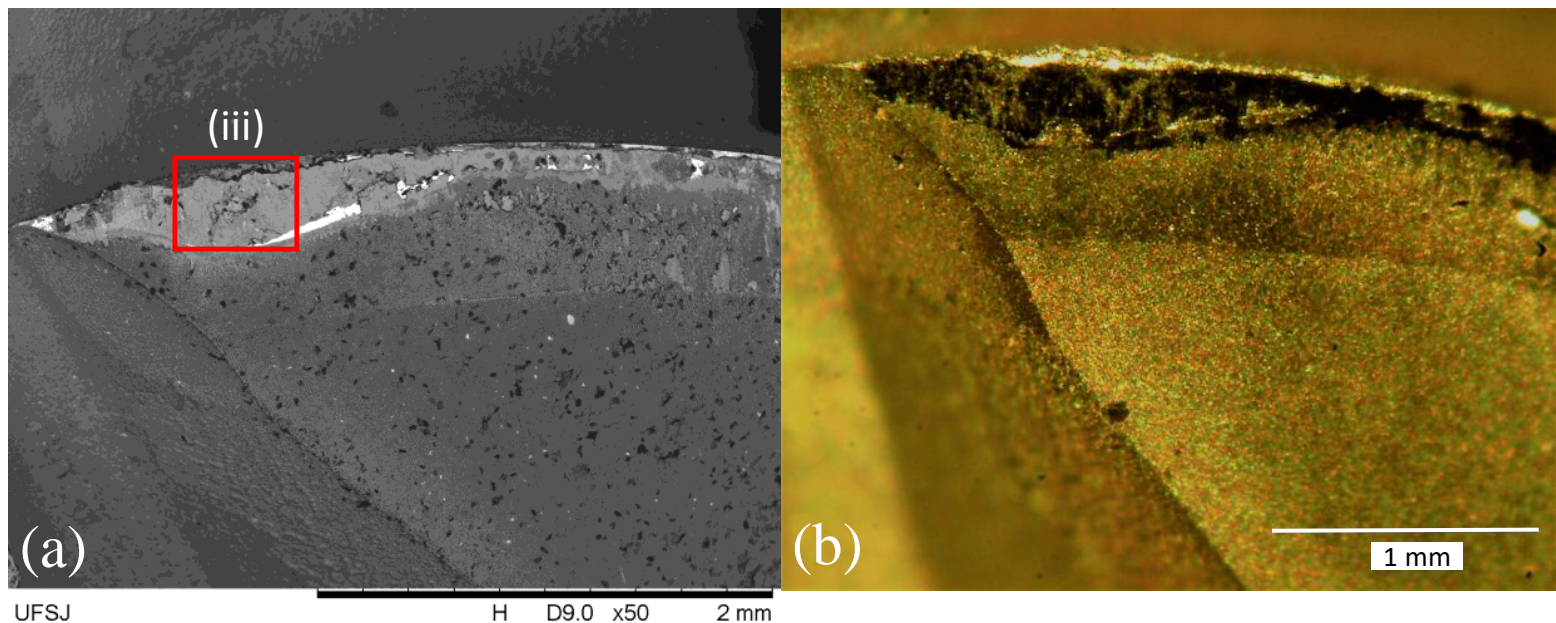

Figure 14. Flank wear, $v_{c}=175 \mathrm{~m} / \mathrm{min}$ (a) SEM, (b) optical microscopy 
Figure 15(a) presents the magnification of the region (iii) of the Figure 14(a), with EDS analysis of the region (vii) in the Figure 15(b). Table 8 presents the percentage of the elements found in the region (vii) associated with Figure 15(b). The high percentage of Fe in this tool, worn with $v_{c}=175 \mathrm{~m} / \mathrm{min}$, characterizes adhesion of the workpiece material in the flank wear of the frontal cutting edges. Arruda and Brandão [22] studied the turning process of API 5L X70 pipeline steel with WC-Co carbide tools. They concluded that the presence of Fe in the worn tool, an element of the workpiece material, is due to the adhesion wear mechanism.
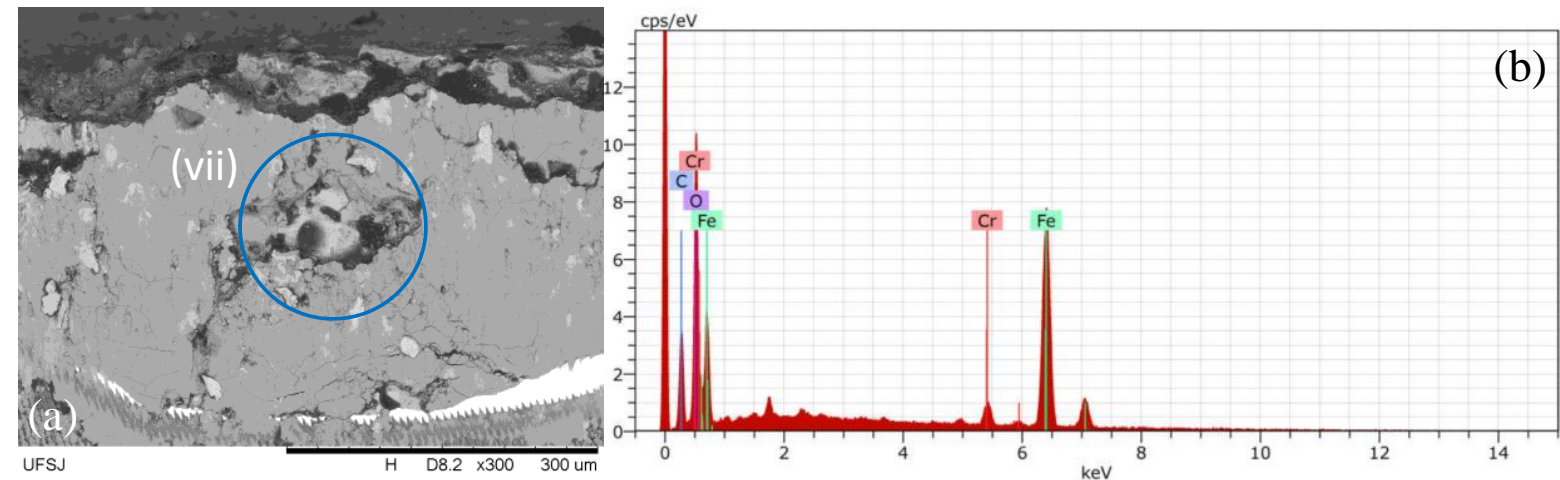

Figure 15. (a) SEM of the region (iii) of the Figure 14(a); (b) EDS of the region (vii)

Table 8. Chemical elements identified by EDS in the region (vii)

\begin{tabular}{lcccc}
\hline \multicolumn{1}{c}{ Element } & $\mathrm{Fe}$ & $\mathrm{O}$ & $\mathrm{C}$ & $\mathrm{Cr}$ \\
\hline$\%$ mass & 53.14 & 25.48 & 18.42 & 2.95 \\
\% atomic & 23.01 & 38.52 & 37.10 & 1.37 \\
\hline
\end{tabular}

Figure 16 presents images obtained by SEM of the periphery of the worn end mill with helical milling tests with $v_{c}=60 \mathrm{~m} / \mathrm{min}$. The region (x) with arrows presents slightly removal of the cover on the peripheral flank of the cutter. The region (ix) of Figure 16(a) is magnified in Figure 16(b), to show in detail the flank face of the nose of the end mill. The colour of the nose flank is similar to the one observed in the flank of the frontal cutting edges, Figure 11(a). It was highlighted two areas in Figure 16(b), (xi) and (xii), in which EDS analyses were performed with the associated spectra in Figures 17(a) and 17(b). 


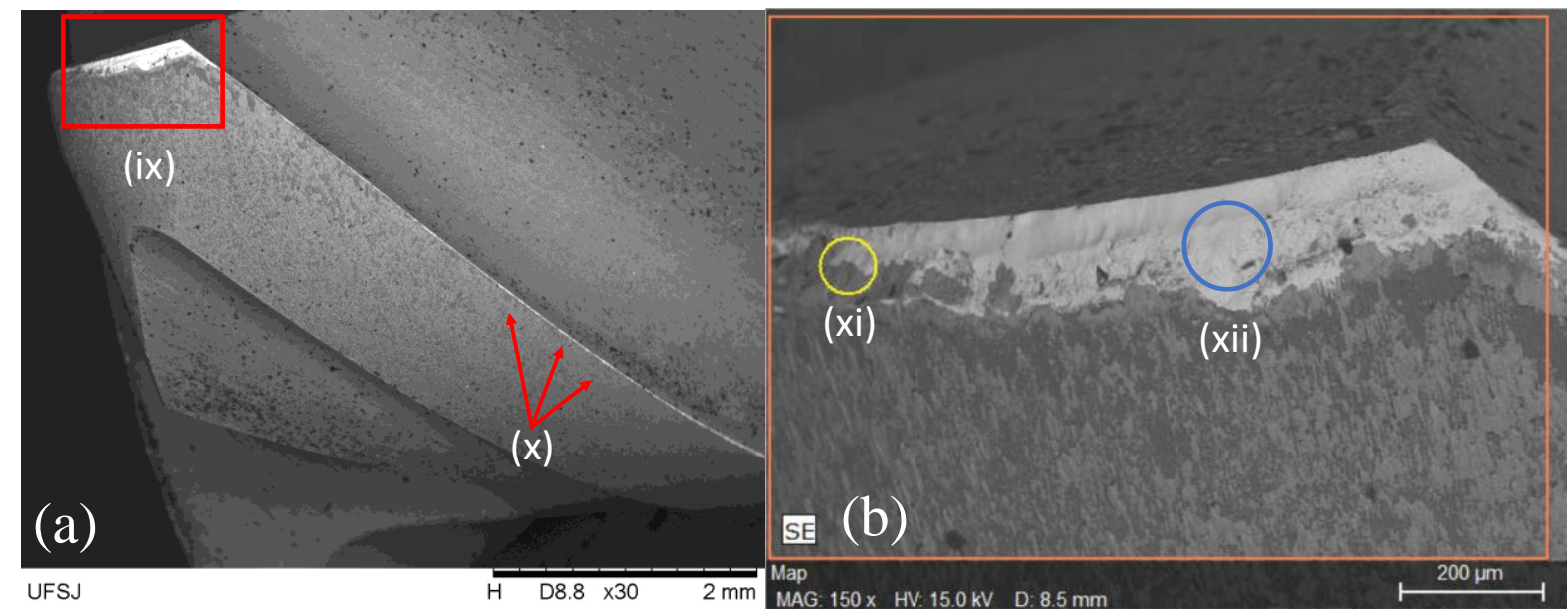

Figure 16. (a) SEM of the peripheral cutting edge, $v_{c}=60 \mathrm{~m} / \mathrm{min}$; (b) detail of the region (ix)
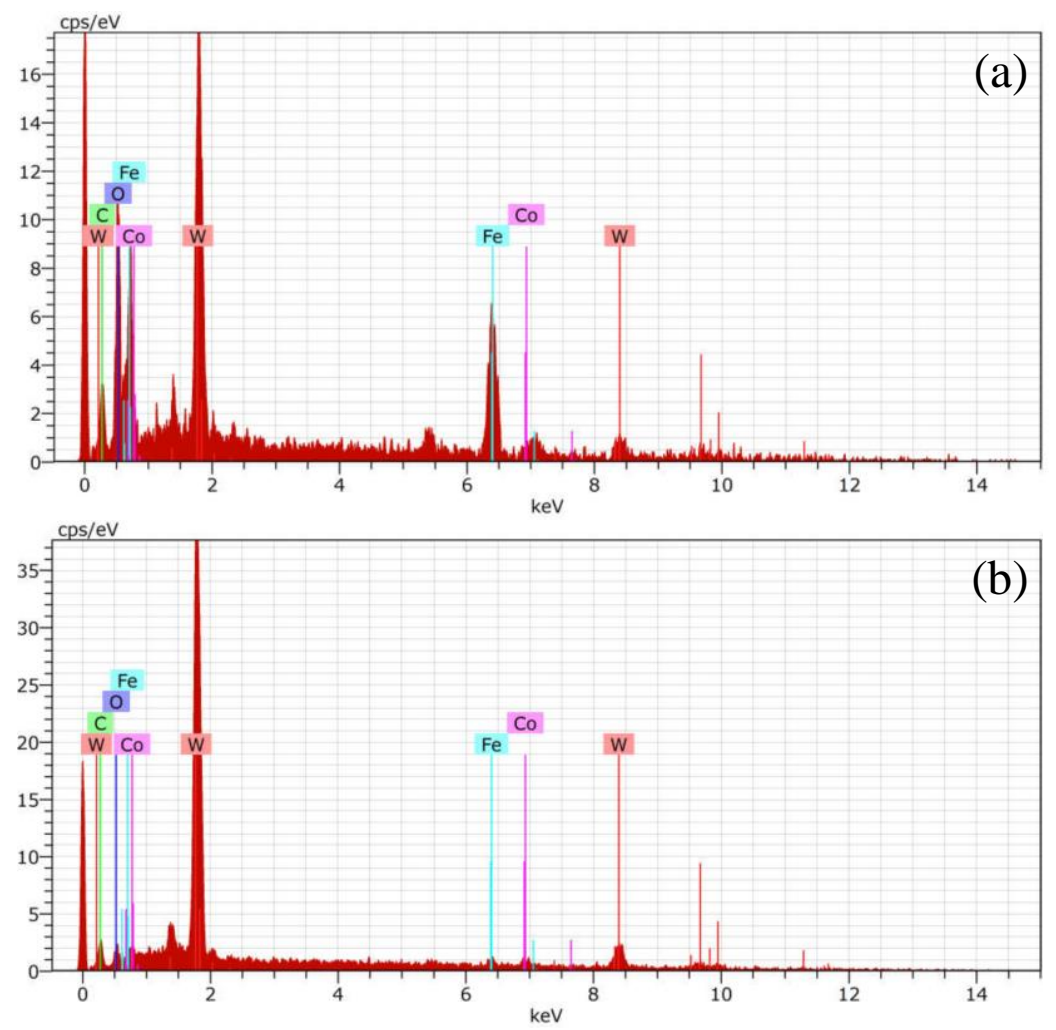

Figure 17. EDS of the (a) region (xi); (b) region (xii) of the Figure 16(b)

Table 9 presents the percentage of elements in the regions (xi) and (xii) of Figure 16(b) observed through EDS. The region (xi), which is darker than the region (xii), presented the tool substrate elements $\mathrm{W}$ and $\mathrm{C}$, the presence of $\mathrm{Fe}$, indicating adhesion, and $\mathrm{O}$, indicating oxides formation with these metallic elements. The region (xii), when compared with the region (xi), presented the higher percentage of the substrate elements 
$\mathrm{W}$ and $\mathrm{C}$, however with a fewer quantity of $\mathrm{Fe}$ and $\mathrm{C}$, due to the small dark spots observed. The presence of Co characterizes the bonding face of the carbide, ensuring toughness and plasticity, as explained by Mao et al. [23] and Wang et al. [24].

Table 9. Elements identified by EDS in the regions (xi) and (xii)

\begin{tabular}{ccccccc}
\hline & Element & $\mathrm{Fe}$ & $\mathrm{W}$ & $\mathrm{O}$ & $\mathrm{C}$ & $\mathrm{Co}$ \\
\hline \multirow{2}{*}{ xi } & \% mass & 31.40 & 28.84 & 25.39 & 13.07 & 1.30 \\
& \% atomic & 16.46 & 4.59 & 46.46 & 31.84 & 0.64 \\
\hline \multirow{2}{*}{ xii } & \% mass & 2.30 & 76.21 & 4.96 & 12.82 & 3.76 \\
& \% atomic & 2.18 & 21.86 & 16.36 & 56.30 & 3.31 \\
\hline
\end{tabular}

Figure 18 presents images obtained by SEM of the periphery of the worn tool with $v_{c}=175 \mathrm{~m} / \mathrm{min}$. The area (xiii) of Figure 18(a) is enlarged in Figure 18(b). EDS analysis was conducted in the peripheral flank, highlighted region (xiv) of Figure 18(a). The pointed region $(\mathrm{xv})$ in this tool worn with $v_{c}=175 \mathrm{~m} / \mathrm{min}$ presented higher coating loss when compared to the tool worn with $v_{c}=60 \mathrm{~m} / \mathrm{min}$, since the increase in $v_{c}$ entails an increase in friction and temperature, increasing the wear rate in the peripheral flank face of the edges. In the enlarged SEM image of the region (xvii), presented in Figure 18(b), it can be observed a fracture in tool nose flank. This fracture may be an effect of mechanical shock conditions with the high speed, $v_{c}=175 \mathrm{~m} / \mathrm{min}$, adopted in this helical milling tool life test, since in this region occurs the highest cutting temperature and cutting speed in helical milling process [14]. In addition, in helical milling, the tangential feed velocity is different according to the point of the cutting edge with regard to the borehole diameter, due to the circular trajectory, differently from the linear end milling. Consequently, when the tool nose tangencies the borehole surface in generation, this region reaches concomitantly the highest cutting velocity and feed velocity in the helical milling process. 


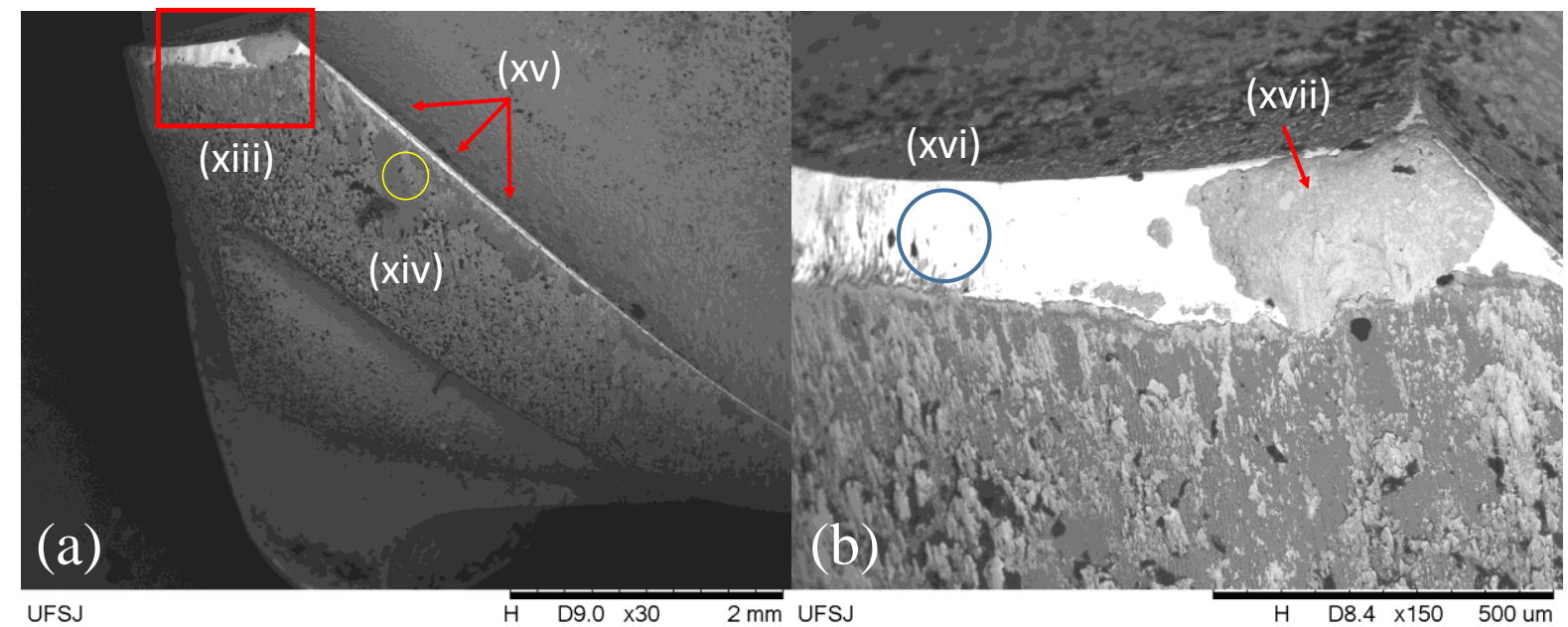

Figure 18. (a) SEM of the peripheral cutting edge, $v_{c}=175 \mathrm{~m} / \mathrm{min}$; (b) detail of the region (xiii)
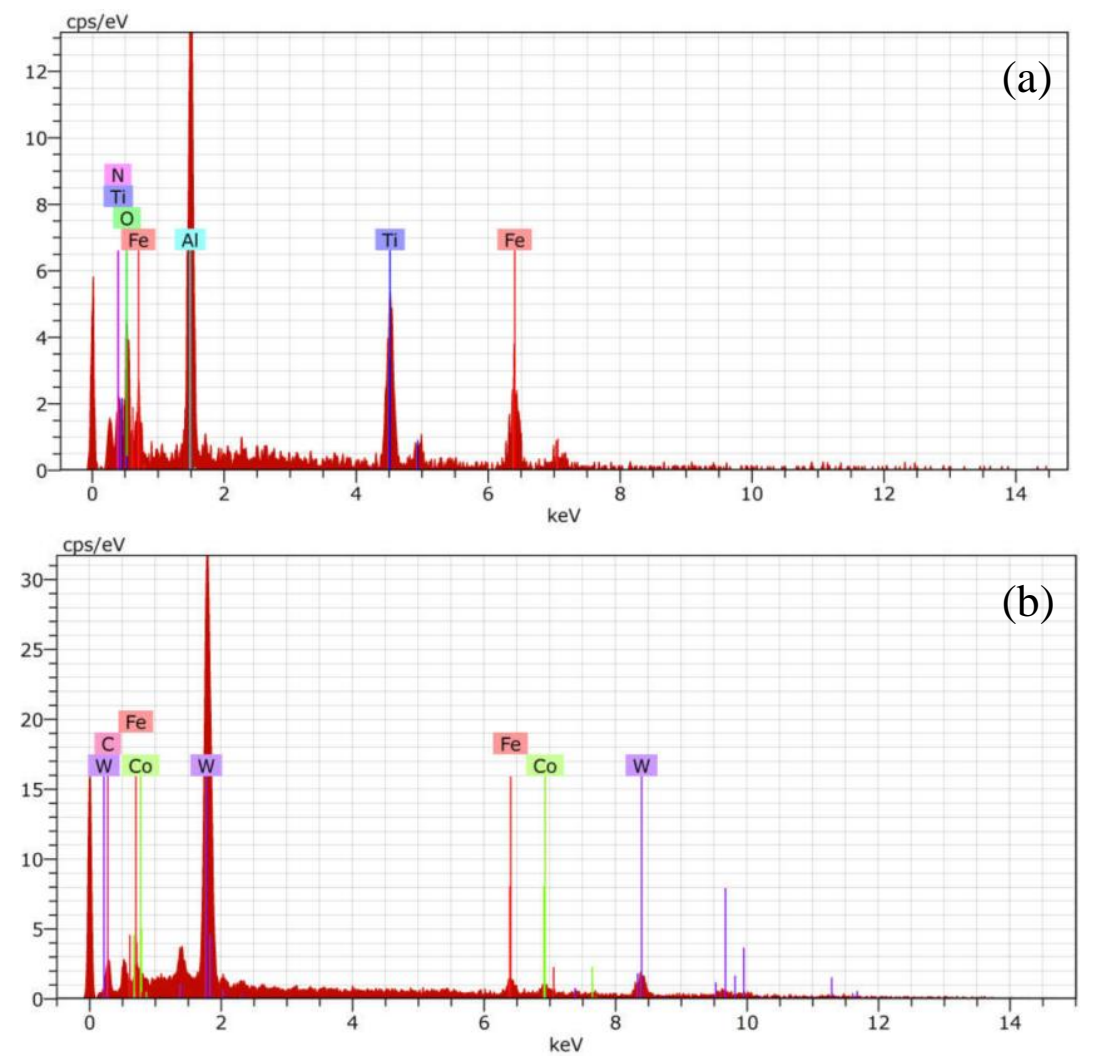

Figure 19. (a) EDS of the region (xiv) of the Figure 18(a); (b) EDS of the region (xvi) of the Figure 18(b)

The EDS spectra of the regions (xiv) and (xvi) of the Figures 18(a) and 18(b), respectively, are in Figure 19, with the percentage of the identified elements through EDS in Table 10. For the region (xiv) it can be observed the presence of the elements of the tool coating $\mathrm{Ti}, \mathrm{Al}$ and $\mathrm{N}$. Besides these elements, which add up to almost $50 \%$ in mass, 
it may be observed $\mathrm{Fe}$ and $\mathrm{O}$ aplenty, characterising the adhesion of Fe followed by oxidation, forming the compound $\mathrm{FeO}$. In the region (xvi) it was observed the presence in abundance of the WC hard phase compound, besides Co of the bounding phase, and Fe in feel quantity due to adhesion of the workpiece material.

Table 10. Elements identified by EDS in the regions (xiv) and (xvi)

\begin{tabular}{ccccccc}
\hline \multirow{3}{*}{ xiv } & Element & $\mathrm{Fe}$ & $\mathrm{O}$ & $\mathrm{Ti}$ & $\mathrm{Al}$ & $\mathrm{N}$ \\
\cline { 2 - 7 } & $\%$ mass & 26.08 & 25.28 & 22.18 & 16.45 & 10.01 \\
& $\%$ atomic & 12.18 & 41.20 & 12.08 & 15.90 & 18.64 \\
\hline \multirow{3}{*}{ xvi } & Element & $\mathrm{W}$ & $\mathrm{C}$ & $\mathrm{Fe}$ & $\mathrm{Co}$ & \\
\cline { 2 - 7 } & $\%$ mass & 72.06 & 18.12 & 6.18 & 3.64 & \\
& $\%$ atomic & 18.90 & 72.78 & 5.34 & 2.98 & \\
\hline
\end{tabular}

It was observed expressive burr formation in the borehole exit with tool wear evolution during helical milling tool life tests in AISI H13 hardened steel. With the flank wear in the periphery of the tool, as observed in Figures 16 and 18, occurs the cutting edges rounding, as observed in the highlighted areas (ix) and (xiii) in these Figures, respectively. Consequently, the tool loses the ability of remove material in the borehole exit, leading to burr formation. Figure 20 presents a result of burr height measurement for the workpiece number 30 machined with $v_{c}=60 \mathrm{~m} / \mathrm{min}$. Table 11 summarizes the burr height measurement for the borehole exit in workpieces machined considering the two cutting velocities and the tool life stage - beginning, middle and end.

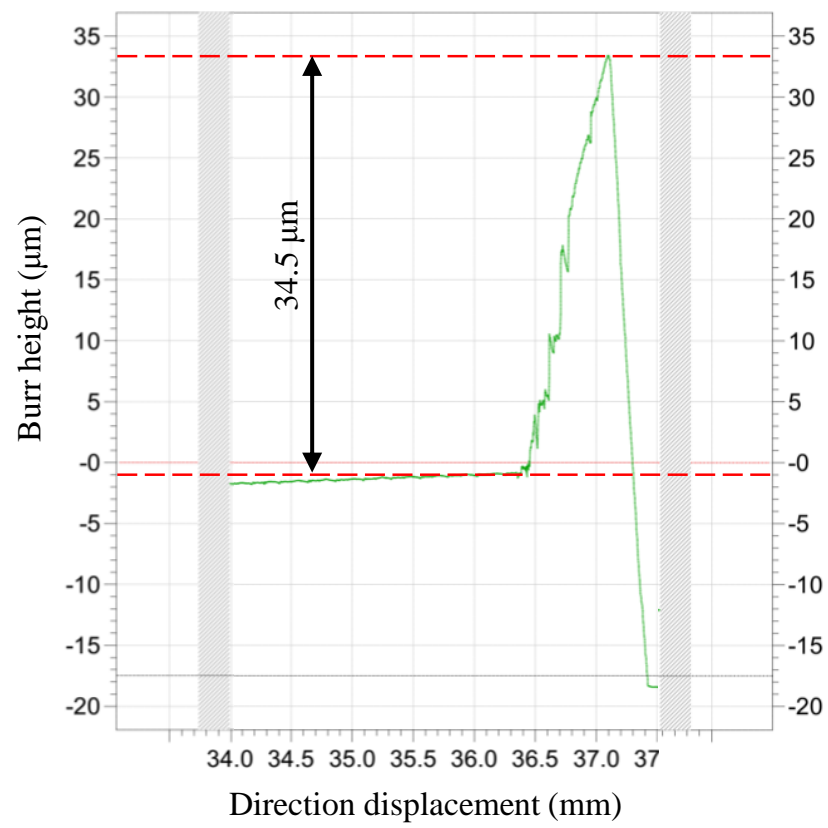

Figure 20. Burr height measurement, workpiece $30, v_{c}=60 \mathrm{~m} / \mathrm{min}$ 
Table 11. Burr height

\begin{tabular}{ccc}
\hline $\begin{array}{c}v_{c} \\
{[\mathrm{~m} / \mathrm{min}]}\end{array}$ & $\begin{array}{c}\text { Tool life } \\
\text { stage }\end{array}$ & $\begin{array}{c}\text { Burr height }(B h) \\
{[\mu \mathrm{m}]}\end{array}$ \\
\hline 60 & Beginning & 0.5 \\
60 & Beginning & 0.8 \\
60 & Beginning & 1.5 \\
60 & Middle & 21.5 \\
60 & Middle & 16.5 \\
60 & Middle & 27.8 \\
60 & End & 33.8 \\
60 & End & 33 \\
60 & End & 34.8 \\
175 & Beginning & 1.8 \\
175 & Beginning & 2.0 \\
175 & Beginning & 1.2 \\
175 & Middle & 32.2 \\
175 & Middle & 23.3 \\
175 & Middle & 27.5 \\
175 & End & 20.2 \\
175 & End & 18.7 \\
175 & End & 20.0 \\
\hline
\end{tabular}

The nested ANOVA for the burr height $(B h)$ was performed with the tool life stage nested under the levels of $v_{c}$. To achieve normality of the residuals, the Box-Cox natural $\log$ transformation, $\lambda=0$, was made. The Anderson-Darling normality test of the residuals was conducted and assured no evidence to reject the normality hypothesis of the residuals, $\mathrm{p}$-value $=0.113$. The homoscedasticity test of Levene reported no difference in the variability of $B h$ between the $v_{c}$ levels within each stage level, with p-value $=0.816$ for the beginning, $\mathrm{p}$-value $=0.759$ for the middle, and $\mathrm{p}$-value $=0.853$ for the end stage of the tool life. Table 12 presents the nested ANOVA for $\ln (B h)$. The goodness-of-fit measures presented good results with $R_{a d j}^{2}=96.61 \%$ and $R_{\text {pred }}^{2}=94.62 \%$. The average burr height presented a difference in means only with regard to the nested factor $\operatorname{stage}\left(v_{c}\right)$. Therefore, the tool life stage within each $v_{c}$ level presented a significant effect in the burr height in the helical milling of AISI hardened steel H13.

The factorial ANOVA is not ideal in this situation since the levels of the factor stage are different when changing the $v_{c}$ level. Then, the explanation of the interaction effect would be difficult and controversial, since the nested factor is not independent. However, it is important to explain that the nested factor presents the sum of squares $S S_{\text {stage }(v c)}$ which accounts for the stage effect and the stage $\times v_{c}$ effect, if a factorial ANOVA were performed, i.e., $S S_{\text {stage }}+S S_{\text {stagexvc }}=37.4711+1.1225=38.5936=S S_{\text {stage }(v c)}$. The 
number of degrees of freedom presents the same property, i.e., $D F_{\text {stage }}+D F_{\text {stagexvc }}=2+2$ $=4=D F_{\text {stage }(v c)}$.

Table 12. Nested ANOVA for $\ln (B h)$

\begin{tabular}{lccccc}
\hline \multicolumn{1}{c}{ Source } & DF & Adj SS & Adj MS & F-Value & P-Value \\
\hline$v_{c}$ & 1 & 0.0643 & 0.06427 & 0.01 & 0.939 \\
stage $\left(v_{c}\right)$ & 4 & 38.5936 & 9.64839 & 122.32 & 0.000 \\
Error & 12 & 0.9465 & 0.07888 & & \\
Total & 17 & 39.6043 & & & \\
\hline \multicolumn{1}{c}{$\mathrm{S}$} & $R^{2}$ & $R_{\text {adj }}^{2}$ & $R_{\text {pred }}^{2}$ & & \\
0.280848 & $97.61 \%$ & $96.61 \%$ & $94.62 \%$ & & \\
\hline
\end{tabular}

Confidence intervals with 0.95 of confidence for the burr height with regard to the tool life stage within $v_{c}$ levels were built and presented in Figure 21. It can be observed the evolution of the burr with regard to the tool life stage for both cutting velocities, however, not in a linear behaviour. The variability of the burr in the workpieces in the beginning and in the end were lower than in the middle of the tool life since in this stage the burr was more brittle. For $v_{c}=175 \mathrm{~m} / \mathrm{min}$, in the end of the tool life, the burr was lower in height, but more homogeneous and robust, due to the high rounding level of the tool nose flank, as observed in Figure 17. Then, in this stage of the tool life, the deburring process would be more difficult.

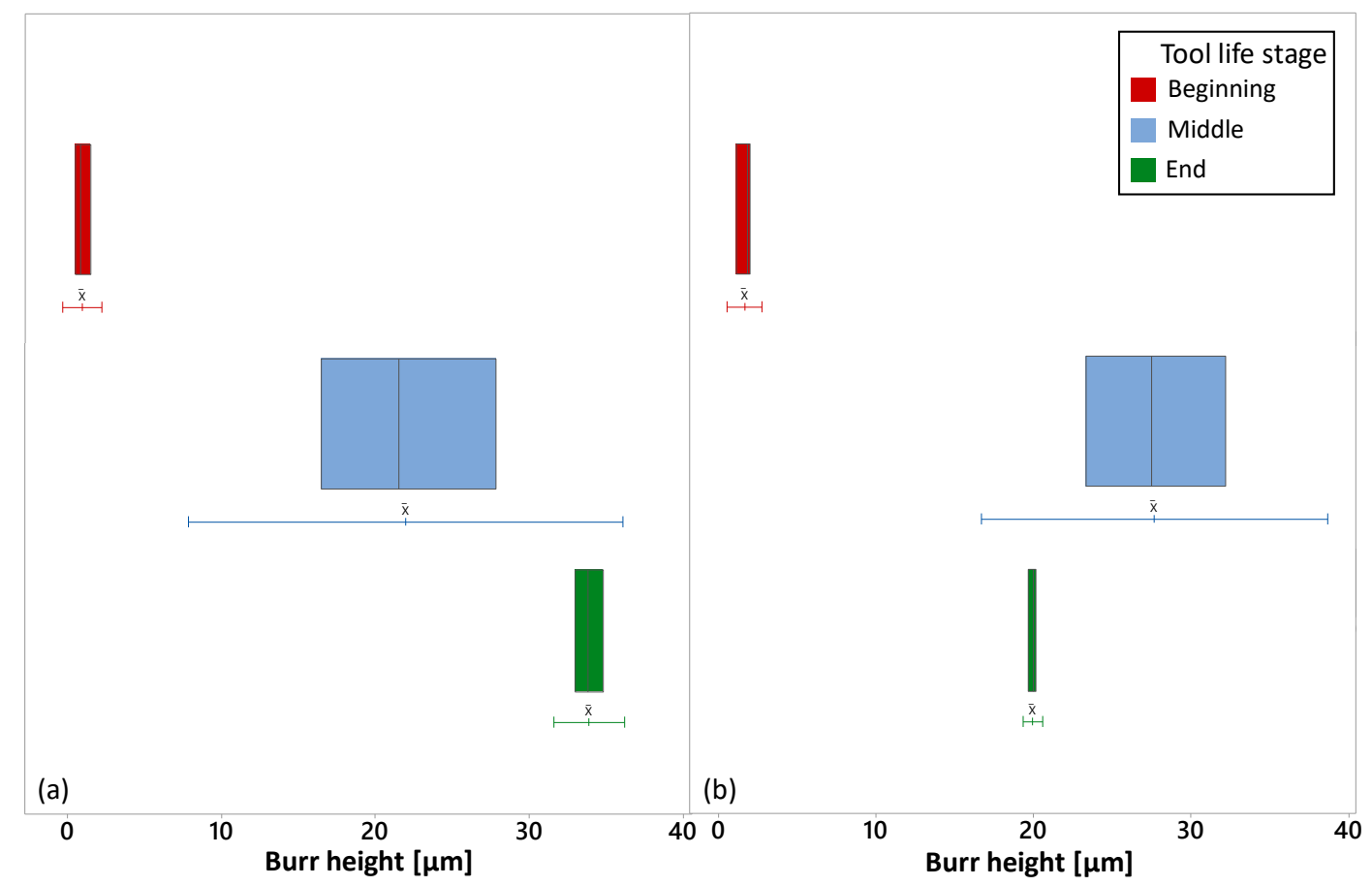

Figure 21. Confidence intervals for burr height (a) $v_{c}=60 \mathrm{~m} / \mathrm{min}$, (b) $v_{c}=175 \mathrm{~m} / \mathrm{min}$ 
Figure 22 shows the caps generated in the exit of the boreholes in the helical milling of AISI H13 hardened steel. The caps generated in all tests are the result of plastic deformation of the material nearby the borehole exit due to the cutting forces in helical milling. It can be observed the difference in colour with regard to cutting velocity and tool life stage. The blue colour indicates the development of high temperatures. The blue colour was more prominent in $v_{c}=175 \mathrm{~m} / \mathrm{min}$ and in the end of the tool life. The obtained caps presented average thickness of $0.48 \mu \mathrm{m}$ with standard deviation of $0.10 \mu \mathrm{m}$. Figure 23 presents the histogram for the cap thickness measurements with confidence intervals for mean and standard deviation, besides normality test with no evidence to reject the null hypothesis of normality of thickness of the caps.

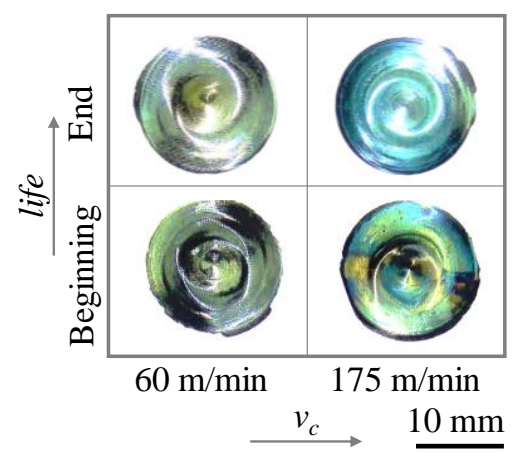

Figure 22. Cap generated in exit of boreholes obtained in helical milling tool life tests in AISI H13 hardened steel
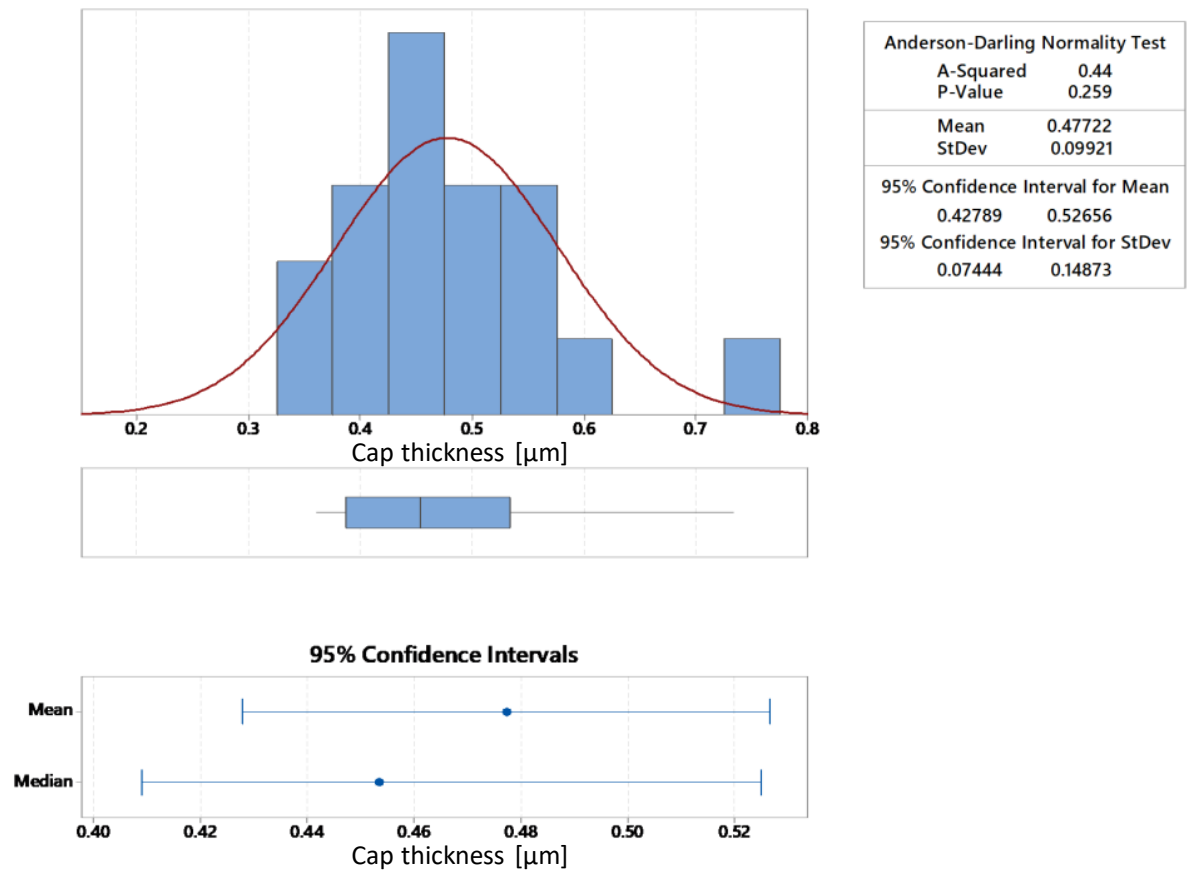

Figure 23. Confidence interval for average cap thickness 


\section{Conclusions}

In this study, helical milling tool life tests were conducted in AISI H13 hardened parts. Considering the average flank wear in the frontal cutting edges as the tool life criteria, $\mathrm{VB}_{\mathrm{B}}=0.15 \mathrm{~mm}, 37$ boreholes were machined with $v_{c}=60 \mathrm{~m} / \mathrm{min}$ and 19 with $v_{c}$ $=175 \mathrm{~m} / \mathrm{min}$, certifying the possibility of achieving several boreholes until the end of the tool life, decreasing tool costs.

The main wear levels were achieved in frontal cutting edges. With both cutting velocities, the main wear mechanisms were adhesion and oxidation. However, with $v_{c}=$ $175 \mathrm{~m} / \mathrm{min}$, the adhesion of workpiece elements was much higher when compared with the adhesion in the tool worn with $v_{c}=60 / \mathrm{min}$. Besides the flank wear in the frontal cutting edges of the tool worn with $v_{c}=60 \mathrm{~m} / \mathrm{min}$ was more regular when compared with the flank wear in the tool worn with $v_{c}=175 \mathrm{~m} / \mathrm{min}$.

In the peripheral cutting edges, for both cutting velocities, it was observed a coating loss in the flank, however with higher levels in the tool worn with $v_{c}=175 \mathrm{~m} / \mathrm{min}$ than the tool worn with $v_{c}=60 \mathrm{~m} / \mathrm{min}$. Adhesion was observed in the clearance surface of the peripheral cutting edges with $v_{c}=175 \mathrm{~m} / \mathrm{min}$.

In one tool nose flank of the tool worn with $v_{c}=175 \mathrm{~m} / \mathrm{min}$ a fracture occurred due to the mechanical shock conditions with the high speed, adopted in this helical milling tool life test, and the highest cutting temperature and cutting speed in this region of the tool during the helical milling process. In addition, in helical milling, the tangential feed velocity is different according to the point of the cutting edge with regard to the borehole diameter, due to the circular trajectory, differently from the linear end milling. Consequently, when the tool nose tangencies the borehole surface in generation, this region reaches concomitantly the highest cutting velocity and feed velocity in helical milling process.

The nested ANOVA showed that the tool life stage was significant in the burr height measured in the borehole exit of AISI H13 hardened steels workpieces. Through confidence intervals it was shown the burr height evolution with regard to the tool life stage nested in each $v_{c}$ level.

\section{ACKNOWLEDGEMENTS}

The authors gratefully acknowledge the Brazilian National Council for Scientific and Technological Development (CNPq), the Coordination of Superior Level Staff 
Improvement (CAPES) and the Research Support Foundation of the State of Minas Gerais (FAPEMIG) for supporting this research. The authors gratefully acknowledge the Foundation for Science and Technology of Portugal (FCT) for supporting the project Sustainable and intelligent manufacturing by machining (FAMASI), process POCI-010145-FEDER-031556. The first author acknowledges CAPES for the PDSE grant, process number 88881.133263/2016-01, the Centre for Mechanical Technology and Automation - TEMA, and Department of Mechanical Engineering of Aveiro University for supporting this research.

\section{References}

1. Brinksmeier, E., Fangmann, S., \& Meyer, I. (2008). Orbital drilling kinematics. Production engineering, 2(3), 277-283.

2. Denkena, B., Boehnke, D., \& Dege, J. H. (2008). Helical milling of CFRP-titanium layer compounds. CIRP Journal of manufacturing Science and Technology, 1(2), 64-69.

3. Iyer, R., Koshy, P., \& Ng, E. (2007). Helical milling: an enabling technology for hard machining precision holes in AISI D2 tool steel. International Journal of Machine Tools and Manufacture, 47(2), 205-210.

4. Zhao, Q., Qin, X., Ji, C., Li, Y., Sun, D., \& Jin, Y. (2015). Tool life and hole surface integrity studies for hole-making of Ti6Al4V alloy. The International Journal of Advanced Manufacturing Technology, 79(5-8), 1017-1026.

5. Sasahara, H., Kawasaki, M., \& Tsutsumi, M. (2008). Helical feed milling with MQL for boring of aluminum alloy. Journal of Advanced Mechanical Design, Systems, and Manufacturing, 2(6), 1030-1040.

6. Eguti, C. C. A., \& Trabasso, L. G. (2014). Design of a robotic orbital driller for assembling aircraft structures. Mechatronics, 24(5), 533-545.

7. Tönshoff, H. K., Spintig, W., König, W., \& Neises, A. (1994). Machining of holes developments in drilling technology. CIRP Annals-Manufacturing Technology, 43(2), 551-561.

8. Saadatbakhsh, M. H., Imani, H., Sadeghi, M. H., \& Farshi, S. S. (2017). Experimental study of surface roughness and geometrical and dimensional tolerances in helical milling of AISI 4340 alloy steel. The International Journal of Advanced Manufacturing Technology, 93(9-12), 4063-4074. 
9. Liu, C., Wang, G., \& Dargusch, M. S. (2012). Modelling, simulation and experimental investigation of cutting forces during helical milling operations. The International Journal of Advanced Manufacturing Technology, 63(9-12), 839-850.

10. Liu, J., Chen, G., Ji, C., Qin, X., Li, H., \& Ren, C. (2014). An investigation of workpiece temperature variation of helical milling for carbon fiber reinforced plastics (CFRP). International Journal of Machine Tools and Manufacture, 86, 89103.

11. Wang, H., Qin, X., Li, H., \& Tan, Y. (2016). A comparative study on helical milling of CFRP/Ti stacks and its individual layers. The International Journal of Advanced Manufacturing Technology, 86(5-8), 1973-1983.

12. Pereira, R. B. D., Brandão, L. C., de Paiva, A. P., Ferreira, J. R., \& Davim, J. P. (2017). A review of helical milling process. International Journal of Machine Tools and Manufacture, 120, 27-48.

13. He, G., Li, H., Jiang, Y., Qin, X., Zhang, X., \& Guan, Y. (2015). Helical milling of CFRP/Ti-6Al-4V stacks with varying machining parameters. Transactions of Tianjin University, 21(1), 56-63.

14. Li, H., He, G., Qin, X., Wang, G., Lu, C., \& Gui, L. (2014). Tool wear and hole quality investigation in dry helical milling of Ti-6Al-4V alloy. The International Journal of Advanced Manufacturing Technology, 71(5-8), 1511-1523.

15. Qin, X., Zhang, X., Li, H., Rong, B., Wang, D., Zhang, H., \& Zuo, G. (2014). Comparative analyses on tool wear in helical milling of Ti-6Al-4V using diamondcoated tool and TiAlN-coated tool. Journal of Advanced Mechanical Design, Systems, and Manufacturing, 8(1), 1-14.

16. Wang, H., Qin, X., Li, H., \& Tan, Y. (2016). A comparative study on helical milling of CFRP/Ti stacks and its individual layers. The International Journal of Advanced Manufacturing Technology, 86(5-8), 1973-1983.

17. Zhao, Q., Qin, X., Ji, C., Li, Y., Sun, D., \& Jin, Y. (2015). Tool life and hole surface integrity studies for hole-making of Ti6Al4V alloy. The International Journal of Advanced Manufacturing Technology, 79(5-8), 1017-1026.

18. Camargo, J. C., Dominguez, D. S., Ezugwu, E. O., \& Machado, Á. R. (2014). Wear model in turning of hardened steel with PCBN tool. International Journal of Refractory Metals and Hard Materials, 47, 61-70. 
19. Wang, B., \& Liu, Z. (2016). Cutting performance of solid ceramic end milling tools in machining hardened AISI H13 steel. International Journal of Refractory Metals and Hard Materials, 55, 24-32.

20. An, Q., Wang, C., Xu, J., Liu, P., \& Chen, M. (2014). Experimental investigation on hard milling of high strength steel using PVD-AlTiN coated cemented carbide tool. International Journal of Refractory Metals and Hard Materials, 43, 94-101.

21. Hintze, W., Steinbach, S., Susemihl, C., \& Kähler, F. (2018). HPC-milling of WCCo cemented carbides with PCD. International Journal of Refractory Metals and Hard Materials, 72, 126-134.

22. Arruda, É. M., \& Brandão, L. C. (2018). Performance study of multilayer carbide tool in high-speed turning of API 5L X70 pipeline steel using a cold air system. The International Journal of Advanced Manufacturing Technology, 94(1-4), 85-103.

23. Mao, C., Ren, Y., Gan, H., Zhang, M., Zhang, J., \& Tang, K. (2015). Microstructure and mechanical properties of cBN-WC-Co composites used for cutting tools. The International Journal of Advanced Manufacturing Technology, 76(9-12), 20432049.

24. Wang, X., Hwang, K. S., Koopman, M., Fang, Z. Z., \& Zhang, L. (2013). Mechanical properties and wear resistance of functionally graded WC-Co. International Journal of Refractory Metals and Hard Materials, 36, 46-51. 